\title{
Quantitative Analysis of Peripheral Benzodiazepine Receptor in the Human Brain Using PET with ${ }^{11} \mathrm{C}-\mathrm{AC}-5216$
}

Michie Miyoshi ${ }^{1,2}$, Hiroshi Ito ${ }^{1}$, Ryosuke Arakawa ${ }^{1}$, Hidehiko Takahashi ${ }^{1}$, Harumasa Takano ${ }^{1}$, Makoto Higuchi $^{1}$, Masaki Okumura $^{1}$, Tatsui Otsuka ${ }^{1}$, Fumitoshi Kodaka ${ }^{1}$, Mizuho Sekine ${ }^{1}$, Takeshi Sasaki ${ }^{1}$, Saori Fujie ${ }^{1}$, Chie Seki ${ }^{1}$, Jun Maeda ${ }^{1}$, Ryuji Nakao ${ }^{3}$, Ming-Rong Zhang ${ }^{3}$, Toshimitsu Fukumura ${ }^{3}$, Masayasu Matsumoto ${ }^{2}$, and Tetsuya Suhara ${ }^{1}$

${ }^{1}$ Molecular Neuroimaging Group, Molecular Imaging Center, National Institute of Radiological Sciences, Chiba, Japan; ${ }^{2}$ Department of Clinical Neuroscience and Therapeutics, Hiroshima University Graduate School of Biomedical Sciences, Hiroshima, Japan; and ${ }^{3}$ Molecular Probe Group, Molecular Imaging Center, National Institute of Radiological Sciences, Chiba, Japan

Peripheral benzodiazepine receptor (PBR) is upregulated in activated glial cells and is therefore a useful biomarker for inflammation in the brain and neurodegenerative disorders. We developed a new PET radioligand, ${ }^{11} \mathrm{C}-\mathrm{AC}-\mathrm{N}$-benzyl- $N$-ethyl-2-(7-methyl8-oxo-2-pheyl-7,8-dihydro-9H-purin-9-yl)acetamide ( ${ }^{11} \mathrm{C}-\mathrm{AC}-$ 5216), that allows the imaging and quantification of PBRs in monkey and mouse brains. The aim of this study was to evaluate a quantification method of ${ }^{11} \mathrm{C}-\mathrm{AC}-5216$ binding in the human brain. Methods: A 90-min dynamic PET scan was obtained for each of 12 healthy men after an intravenous injection of ${ }^{11} \mathrm{C}$ AC-5216. Regions of interest were drawn on several brain regions. Binding potential, compared with nondisplaceable uptake $\left(\mathrm{BP}_{\mathrm{ND}}\right)$, was calculated by a nonlinear least-squares fitting (NLS) method with the 2-tissue-compartment model, and total volume of distribution $\left(V_{T}\right)$ was estimated by NLS and graphical analysis methods. Results: $\mathrm{BP}_{\mathrm{ND}}$ was highest in the thalamus (4.6 \pm 1.0$)$ and lowest in the striatum $(3.5 \pm 0.7)$. $\mathrm{V}_{\mathrm{T}}$ obtained by NLS or graphical analysis showed regional distribution similar to $\mathrm{BP}_{\mathrm{ND}}$. However, there was no correlation between $\mathrm{BP}_{\mathrm{ND}}$ and $\mathrm{V}_{\mathrm{T}}$ because of the interindividual variation of $K_{1} / k_{2}$. BP $\mathrm{ND}_{\mathrm{ND}}$ obtained with data from a scan time of $60 \mathrm{~min}$ was in good agreement with that from a scan time of $90 \mathrm{~min}(r=0.87)$. Conclusion: Regional distribution of ${ }^{11} \mathrm{C}-\mathrm{AC}-5216$ was in good agreement with previous PET studies of PBRs in the human brain. $B P_{N D}$ is more appropriate for estimating ${ }^{11} \mathrm{C}-\mathrm{AC}-5216$ binding than is $\mathrm{V}_{\mathrm{T}}$ because of the interindividual variation of $K_{1} / k_{2}$. ${ }^{11} \mathrm{C}-\mathrm{AC}-$ 5216 is a promising PET ligand for quantifying PBR in the human brain.

Key Words: ${ }^{11} \mathrm{C}-\mathrm{AC}-5216$; peripheral benzodiazepine receptor; microglia; human brain; positron emission tomography

J Nucl Med 2009; 50:1095-1101

DOI: 10.2967/jnumed.109.062554

Received Jan. 26, 2009; revision accepted Mar. 12, 2009. For correspondence or reprints contact: Hiroshi Ito, Molecular Neuroimaging Group, Molecular Imaging Center, National Institute of Radiological Sciences 4-9-1, Anagawa, Inage-ku, Chiba, 263-8555, Japan.

E-mail: hito@nirs.go.jp

COPYRIGHT @ 2009 by the Society of Nuclear Medicine, Inc.
$\mathbf{P}$ eripheral benzodiazepine receptor (PBR) is pharmacologically distinct from central benzodiazepine receptor (CBR). PBR is primarily found on mitochondrial membranes in various peripheral organs $(1-4)$ and is mainly located in glial cells in the brain; its expression was found to be increased in activated microglia in vivo by brain injury $(5,6)$. The increase in PBR density has thus been used as an indicator of neuronal damage and neurodegenerative disorders, such as Alzheimer disease $(7,8)$. These findings then gave impetus to the development of an imaging agent labeled with a radioisotope, making it possible to visualize the distribution of PBR also in the animal brain in vivo (9-11). Specific radiolabeled ligands for PBR, such as ${ }^{11} \mathrm{C}$-PK11195 and ${ }^{11} \mathrm{C}$-DAA1106, have been used in many clinical studies. ${ }^{11} \mathrm{C}-\mathrm{PK} 11195$ was first developed to characterize PBR in the human brain (12). ${ }^{11} \mathrm{C}$-PK11195 binding was reported to have increased in the stroke region (13), plaque of multiple sclerosis (14-16), brain of Alzheimer disease $(17,18)$, and epileptic foci (19). However, the relatively low uptake of ${ }^{11}$ C-PK11195 in the brain limited its wider application $(20,21)$. Therefore, to characterize PBR precisely using PET with advantages over ${ }^{11} \mathrm{C}-\mathrm{PK} 11195$, we developed 2 novel radioligands, ${ }^{11} \mathrm{C}$ DAA1106 $(22,23)$ and ${ }^{18}$ F-FEDAA1106 (24). These ligands exhibited more potent in vitro binding affinity for PBR than did PK11195 and displayed high selectivity against other receptors, including CBR $(24,25)$. In vivo studies demonstrated that these ligands had higher uptake and specific binding in rodent and primate brains than did ${ }^{11} \mathrm{C}$ PK11195 (22-24). We have reported a kinetic analysis method for ${ }^{11} \mathrm{C}$-DAA1106 and ${ }^{18} \mathrm{~F}$-FEDAA1106 binding in the human brain $(26,27)$ and a broad increase of PBR binding in the Alzheimer disease brain using ${ }^{11}$ C-DAA1106 (28).

$N$-benzyl- $N$-ethyl-2-(7-methyl-8-oxo-2-pheyl-7,8-dihydro9H-purin-9-yl)acetamide (AC-5216) is a new candidate as a PET ligand for PBR (29). Affinity of AC-5216 for PBR 
(inhibition constant, $0.297 \mathrm{nM}$ ) was higher than PK11195 $(0.602 \mathrm{nM})(29)$ and lower than DAA1106 (36-108 pM) (30). AC-5216 exhibited negligible affinity for CBR and other receptors, monoamine transporters, and ion channels. The synthesis of ${ }^{11} \mathrm{C}$-labeled AC-5216 $\left({ }^{11} \mathrm{C}-\mathrm{AC}-5216\right)$ and its high accumulation in the mouse brain have been reported (31). A PET study in monkeys demonstrated high uptake of ${ }^{11} \mathrm{C}-\mathrm{AC}-5216$ in the brain, and the binding was inhibited by unlabeled AC-5216 and PK11195 (31). ${ }^{11} \mathrm{C}-$ AC-5216 can be used for the clinical investigation of PBR expression and therefore also microglia activation in neurologic diseases, but the quantification method of ${ }^{11} \mathrm{C}-\mathrm{AC}$ 5216 binding in the living human brain has not yet been established. In the present study, PET measurements with ${ }^{11} \mathrm{C}$-AC-5216 were performed on healthy human subjects. We evaluated kinetic analysis methods for the quantification of ${ }^{11} \mathrm{C}-\mathrm{AC}-5216$ binding in the human brain.

\section{MATERIALS AND METHODS}

\section{Subjects}

Twelve male healthy volunteers (age range, $20-33$ y; mean age \pm $\mathrm{SD}, 24.6 \pm 4.5 \mathrm{y})$ participated in this study. All volunteers were free of any somatic, neurologic, or psychiatric disorders, and they had no history of current or previous drug abuse. This study was approved by the ethics and radiation safety committees of the National Institute of Radiologic Sciences. Written informed consent was obtained from each subject.

\section{Radioligand Preparation}

${ }^{11} \mathrm{C}-\mathrm{AC}-5216$ was synthesized as described previously (31). In brief, AC-5216 and its desmethyl precursor were synthesized starting from commercially available compounds. ${ }^{11} \mathrm{C}-\mathrm{AC}-5216$ was radiosynthesized through the reaction of the precursor with ${ }^{11} \mathrm{C}-\mathrm{CH}_{3} \mathrm{I}$ in the presence of sodium hydride.

\section{PET}

An ECAT EXACT HR + PET scanner system (CTI-Siemens) was used for all measurements. A head-fixation device was used to minimize head movement. A transmission scan for attenuation correction was obtained using a ${ }^{68} \mathrm{Ge} /{ }^{68} \mathrm{Ga}$ source. Dynamic PET scans were obtained after a 1-min intravenous slow bolus injection of ${ }^{11} \mathrm{C}-\mathrm{AC}-5216$ (354.6-385.1 MBq [372.8 \pm 9.7 MBq]). The specific radioactivities were 93.7-224.2 GBq/ $\mu$ mol $(148.2 \pm 35.6$ $\mathrm{GBq} / \mu \mathrm{mol})$ at the time of injection. Brain radioactivities were measured from 0 to $90 \mathrm{~min}(20 \mathrm{~s} \times 9,60 \mathrm{~s} \times 5,120 \mathrm{~s} \times 4,240 \mathrm{~s} \times$ 11 , and $300 \mathrm{~s} \times 6$ ). MR images of the brain were acquired with a 1.5-T MRI scanner (Gyroscan NT; Philips). T1-weighted images were obtained at $1-\mathrm{mm}$ slices.

\section{Arterial Blood Sampling}

To obtain the arterial input function, arterial blood samples were taken manually 32 times $(10,20,30,40,50,60,70,80,90$, $100,110,120$, and $150 \mathrm{~s}$ and $3,4,5,6,7,8,9,10,12,15,20,25$, $30,40,50,60,70,80$, and $90 \mathrm{~min}$ after the radiotracer injection) during the PET scan. Each blood sample was centrifuged to obtain plasma and blood cell fractions, and the concentrations of radioactivity in whole blood and plasma were measured. Plasma protein binding was not determined in this study.

The percentage of unchanged ${ }^{11} \mathrm{C}-\mathrm{AC}-5216$ in plasma was determined by high-performance liquid chromatography (HPLC) in 10 blood samples $(3,10,20,30,40,50,60,70,80$, and 90 min after injection). Acetonitrile was added to each plasma sample, and the samples were then centrifuged. The supernatant was subjected to radio-high-performance liquid chromatography analysis (column, XBridge Prep C18 [Waters]; mobile phase, 50\% acetonitrile). The plasma input function was defined as the radioactivity of plasma multiplied by the percentage of unchanged radioligand.

\section{Regions of Interest (ROIs)}

All MR images were coregistered to PET images using PMOD (version 2.8; PMOD Technologies). Eleven ROIs were drawn manually on the PET images with reference to coregistered MR images. ROIs were delineated for the cerebellum, dorsolateral prefrontal cortex, medial prefrontal cortex, parietal cortex, lateral temporal cortex, medial temporal cortex, occipital cortex, anterior cingulate cortex, posterior cingulate cortex, striatum, and thalamus.

\section{Kinetic Model of ${ }^{11} \mathrm{C}-\mathrm{AC}-5216$}

To describe the kinetics of ${ }^{11} \mathrm{C}-\mathrm{AC}-5216$ in the brain, the 2-tissue-compartment model with 4 rate constants $\left(K_{1}, k_{2}, k_{3}\right.$, and $k_{4}$ ) was used (32). The 3 compartments were defined as follows: $\mathrm{C}_{\mathrm{P}}$, the radioactivity concentration of unchanged radioligand in plasma (arterial input function); $\mathrm{C}_{\mathrm{ND}}$, the radioactivity concentration of nondisplaceable radioligand in brain, including nonspecifically bound and free radioligand; and $\mathrm{C}_{\mathrm{S}}$, the radioactivity concentration of radioligand specifically bound to receptors. The rate constants $K_{1}$ and $k_{2}$ represent the influx and efflux rates for radioligand diffusion through the blood-brain barrier. The rate constants $k_{3}$ and $k_{4}$ represent the radioligand transfers between the compartments for nondisplaceable and specifically bound radioligand. This model can be described by the following equations:

$$
\begin{array}{cc}
\mathrm{dC}_{\mathrm{ND}}(\mathrm{t}) / \mathrm{dt}=\mathrm{K}_{1} \mathrm{C}_{\mathrm{P}}(\mathrm{t})-\left(k_{2}+k_{3}\right) \mathrm{C}_{\mathrm{ND}}(\mathrm{t})+k_{4} \mathrm{C}_{\mathrm{S}}(\mathrm{t}) & \text { Eq. } 1 \\
\mathrm{dC}_{\mathrm{S}}(\mathrm{t}) / \mathrm{dt}=k_{3} \mathrm{C}_{\mathrm{ND}}(\mathrm{t})-k_{4} \mathrm{C}_{\mathrm{S}}(\mathrm{t}) & \text { Eq. } 2 \\
\mathrm{C}_{\mathrm{T}}(\mathrm{t})=\mathrm{C}_{\mathrm{ND}}(\mathrm{t})+\mathrm{C}_{\mathrm{S}}(\mathrm{t}) . & \text { Eq. } 3
\end{array}
$$

$\mathrm{C}_{\mathrm{T}}(\mathrm{t})$ is the total radioactivity concentration in a brain region measured by PET. In this analysis, blood volume $\left(\mathrm{V}_{\mathrm{b}}\right)$ was fixed to be $0.05 \mathrm{~mL} / \mathrm{mL}(26)$.

\section{Calculation of ${ }^{11} \mathrm{C}-\mathrm{AC}-5216$ Binding}

In the nonlinear least-squares fitting (NLS) method, ${ }^{11} \mathrm{C}-\mathrm{AC}$ 5216 bindings were expressed as binding potentials relative to nondisplaceable binding $\left(\mathrm{BP}_{\mathrm{ND}}\right)$. $\mathrm{BP}_{\mathrm{ND}}$ can be expressed as:

$$
\mathrm{BP}_{\mathrm{ND}}=\mathrm{f}_{\mathrm{ND}} \mathrm{B}_{\max } / \mathrm{K}_{\mathrm{d}}=k_{3} / k_{4} . \quad \text { Eq. } 4
$$

$B_{\text {max }}$ is the receptor density, $1 / K_{d}$ is the affinity, and $f_{N D}$ is the free fraction of ligand in the nondisplaceable tissue compartment. We also calculated the total distribution volume $\left(\mathrm{V}_{\mathrm{T}}\right)$, which can be expressed as:

$$
\mathrm{V}_{\mathrm{T}}=K_{1} / k_{2}\left(1+k_{3} / k_{4}\right)
$$

In the graphical analysis (GA) method, GA yields $V_{T}$ from the arterial input function and the tissue time-activity curve (33). Parameters are estimated from the equation: 


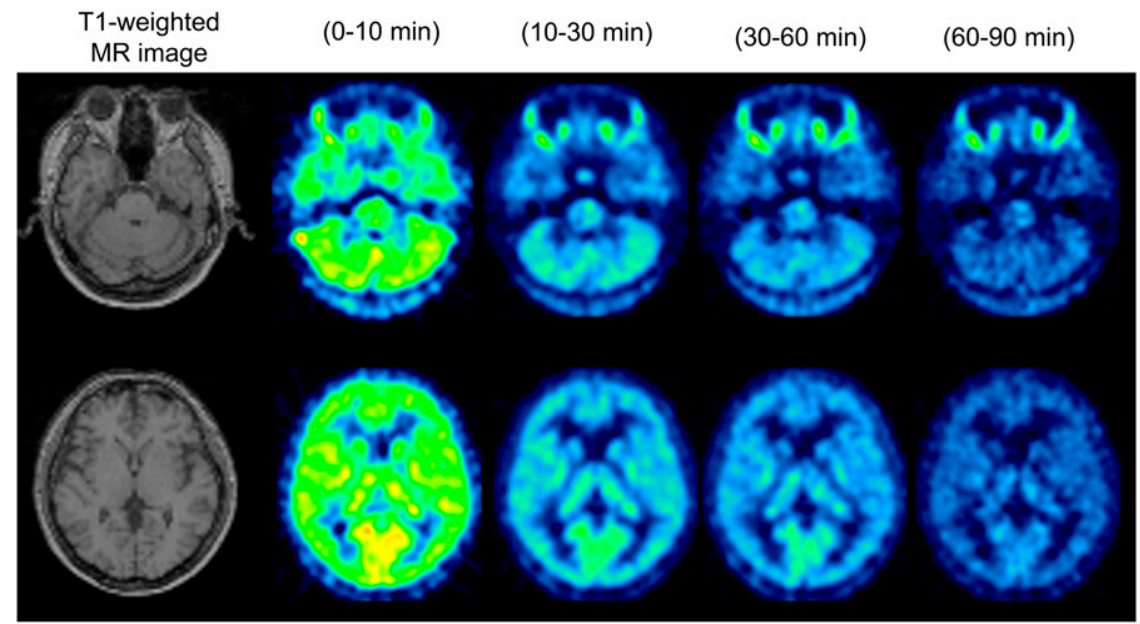

FIGURE 1. Typical summated PET images from 0 to 10,10 to 30,30 to 60 , and 60 to $90 \mathrm{~min}$ of ${ }^{11} \mathrm{C}-\mathrm{AC}-5216$ and T1-weighted MR images.

$$
\frac{\int_{0}^{\mathrm{T}} \mathrm{CT}(\mathrm{t}) \mathrm{dt}}{\mathrm{CT}(\mathrm{T})}=\mathrm{V} \frac{\int_{0}^{\mathrm{T}} \mathrm{CP}(\mathrm{t}) \mathrm{dt}}{\mathrm{CT}(\mathrm{T})}+\mathrm{b} \text { for } T>\mathrm{t} *
$$

where $V$ represents $V_{T}$ after equilibration time $t^{*}$. Because $b$ becomes constant only after equilibration time $t^{*}, \mathrm{~V}$ and $\mathrm{b}$ are estimated as a slope and an intercept, respectively, using the points of $\mathrm{T}>\mathrm{t}^{*}$. The starting time for linear regression $\mathrm{t}^{*}$ was set at 30 $\min$.

In these methods, the PET scan data for 90 min and those for 60 min were used. For these analyses, PMOD was used.

\section{RESULTS}

Typical summated PET images (0-10, 10-30, 30-60, and 60-90 $\mathrm{min}$ ) and T1-weighted MR images are shown in Figure 1. The distribution of radioactivity was widespread and fairly uniform in the gray matter of the cerebral cortices and cerebellum, striatum, and thalamus. Typical

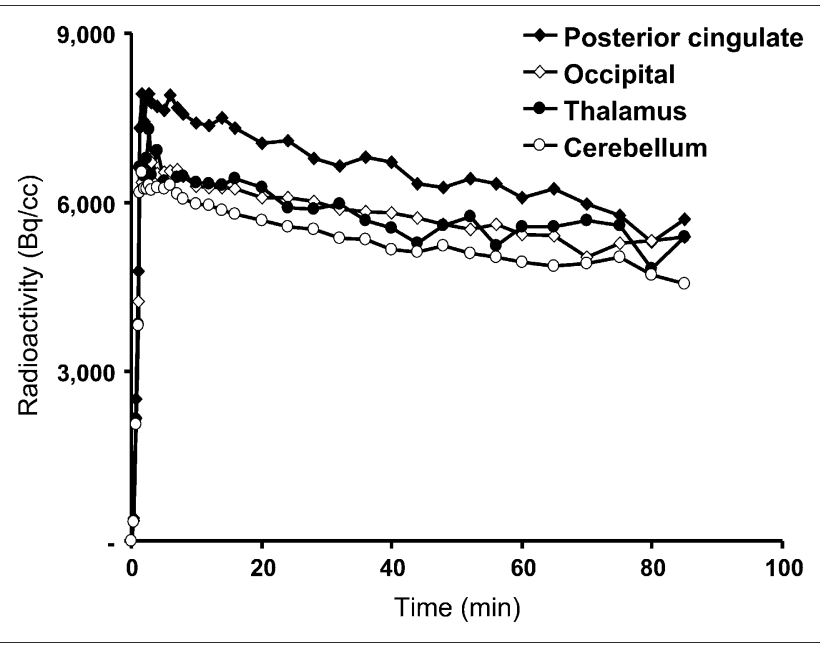

FIGURE 2. Typical time-activity curves of ${ }^{11} \mathrm{C}-\mathrm{AC}-5216$ in occipital cortex, posterior cingulate cortex, thalamus, and cerebellum. time-activity curves of measured brain regions are shown in Figure 2. After an intervenous injection of ${ }^{11} \mathrm{C}-\mathrm{AC}-5216$, radioactivity peaked at about $2-3 \mathrm{~min}$, followed by slow washout. The average percentage of unchanged ${ }^{11} \mathrm{C}-\mathrm{AC}$ 5216 in plasma was $99.8 \% \pm 0.2 \%$ at $3 \mathrm{~min}, 89.1 \% \pm$ $4.5 \%$ at $30 \mathrm{~min}$, and $69.6 \% \pm 12.0 \%$ at $90 \mathrm{~min}$ (mean \pm SD) (Fig.3).

The $K_{1}, K_{1} / k_{2}, k_{3}, k_{3} / k_{4}$, and $\mathrm{V}_{\mathrm{T}}$ values estimated by NLS and $\mathrm{V}_{\mathrm{T}}$ estimated by GA are listed in Tables 1 and 2 for scan times of 90 and $60 \mathrm{~min}$, showing the mean and coefficient of variation (COV) (SD/mean [\%]) of all ROIs. Although the mean $\mathrm{V}_{\mathrm{T}}$ values estimated by GA were larger than those by NLS in all regions, good correlation was observed between them ( $r=0.93, P<0.001)$ (Fig. 4). However, no correlation was observed between $\mathrm{BP}_{\mathrm{ND}}$

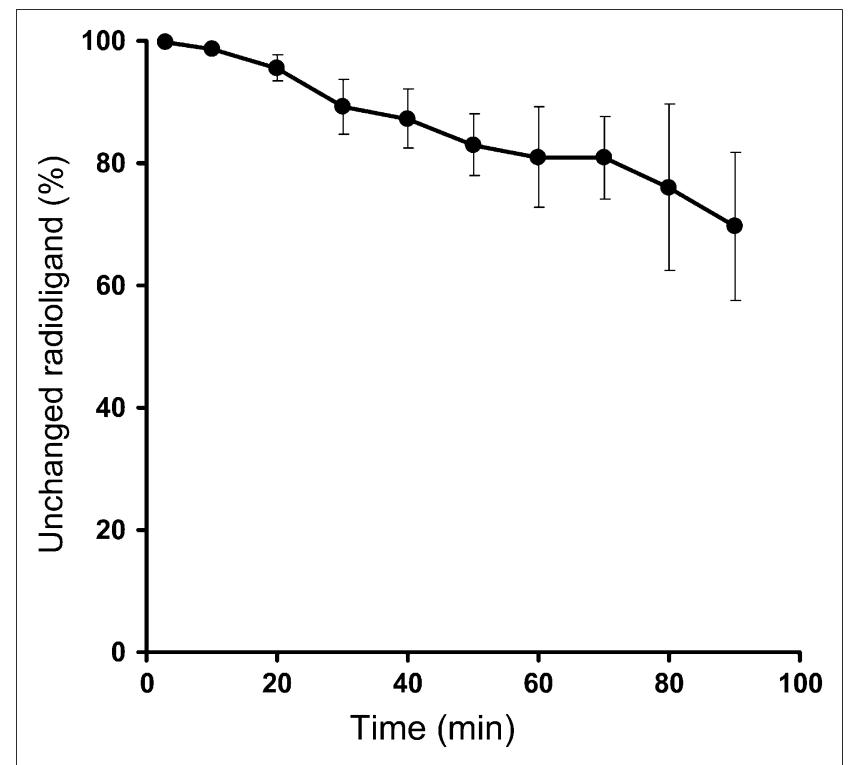

FIGURE 3. Average percentage of unchanged ${ }^{11} \mathrm{C}-\mathrm{AC}-$ 5216 in plasma. Bars indicate SD. 
TABLE 1. Average Values of Parameters Estimated by Each Method with 90-Minute Scan Time $(n=12)$

\begin{tabular}{|c|c|c|c|c|c|c|}
\hline \multirow[b]{3}{*}{ Region } & \multicolumn{6}{|c|}{ Method } \\
\hline & \multicolumn{5}{|c|}{ NLS } & \multirow[b]{2}{*}{$\mathrm{GA}\left(\mathrm{V}_{\mathrm{T}}\right)$} \\
\hline & $K_{1}$ & $K_{1} / k_{2}$ & $k_{3}$ & $k_{3} / k_{4}$ & $\mathrm{~V}_{\mathrm{T}}$ & \\
\hline Cerebellum & $0.184(24.4)$ & $1.40(28.7)$ & $0.091(32.8)$ & $4.25(26.7)$ & $5.70(25.5)$ & $6.64(22.9)$ \\
\hline Dorsolateral frontal & $0.174(29.8)$ & $1.60(22.6)$ & $0.072(25.7)$ & $3.47(19.4)$ & $5.49(25.1)$ & $6.40(22.5)$ \\
\hline Medial frontal & 0.171 (28.2) & $1.46(19.5)$ & $0.079(24.4)$ & $3.61(20.9)$ & $5.21(26.6)$ & $6.14(24.0)$ \\
\hline Parietal & $0.175(27.6)$ & 1.55 (19.3) & $0.076(23.2)$ & $3.53(20.5)$ & $5.41(25.2)$ & $6.42(22.4)$ \\
\hline Lateral temporal & $0.170(27.2)$ & $1.50(22.5)$ & $0.079(24.0)$ & $3.75(23.0)$ & $5.49(25.8)$ & $6.45(22.8)$ \\
\hline Medial temporal & $0.146(28.1)$ & $1.33(25.8)$ & $0.077(31.2)$ & $4.40(28.6)$ & $5.72(31.4)$ & $6.08(27.9)$ \\
\hline Occipital & 0.197 (23.6) & $1.47(24.7)$ & $0.097(22.5)$ & 4.18 (19.3) & $6.08(30.0)$ & 7.08 (25.4) \\
\hline Anterior cingulate & $0.172(30.8)$ & $1.38(23.8)$ & 0.075 (32.6) & $4.11(26.9)$ & $5.58(28.9)$ & $6.22(25.3)$ \\
\hline Posterior cingulate & 0.222 (23.9) & $1.44(34.4)$ & 0.110 (30.3) & $4.37(24.6)$ & $5.97(28.0)$ & 7.08 (25.9) \\
\hline Striatum & $0.159(22.5)$ & $1.43(17.6)$ & $0.074(23.1)$ & $3.46(20.2)$ & $4.94(30.3)$ & $5.66(22.4)$ \\
\hline Thalamus & $0.188(29.6)$ & $1.51(24.2)$ & 0.085 (34.9) & $4.64(20.5)$ & $6.86(26.0)$ & $7.39(24.7)$ \\
\hline
\end{tabular}

estimated by NLS and $\mathrm{V}_{\mathrm{T}}$ estimated by NLS or GA for all regions ( $\mathrm{V}_{\mathrm{T}}$ by NLS, $r=0.31$; $\mathrm{V}_{\mathrm{T}}$ by GA, $r=0.19$ ) (Figs. $5 \mathrm{~A}$ and $5 \mathrm{~B})$. $\mathrm{BP}_{\mathrm{ND}}$ values estimated by NLS with a scan time of 60 min were in good agreement with those with a scan time of $90 \mathrm{~min}(r=0.87, P<0.001)$ (Fig. 6). $\mathrm{V}_{\mathrm{T}}$ values estimated by NLS or GA with a scan time of $60 \mathrm{~min}$ were in good agreement with those with a scan time of 90 $\min \left(\mathrm{V}_{\mathrm{T}}\right.$ by NLS, $r=0.82, P<0.001$; $\mathrm{V}_{\mathrm{T}}$ by GA, $r=$ $0.92, P<0.001)$.

\section{DISCUSSION}

This study describes the first, to our knowledge, quantitative analysis of PET measurement with ${ }^{11} \mathrm{C}-\mathrm{AC}-5216$ for PBR binding in the living human brain. Intravenous injection of ${ }^{11} \mathrm{C}-\mathrm{AC}-5216$ showed radioactivity to peak at about 2-3 min, followed by slow washout, similar to the pattern of ${ }^{11} \mathrm{C}$-DAA1106 in animal (31) and human studies (26). $\mathrm{BP}_{\mathrm{ND}}$ was highest in the thalamus in this study, consistent with ${ }^{11} \mathrm{C}$-PK11195 (18) and ${ }^{11} \mathrm{C}$-DAA1106 (26) studies. $\mathrm{BP}_{\mathrm{ND}}$ was relatively higher in the medial temporal cortex and cerebellum and lower in the striatum, which was also consistent with ${ }^{11} \mathrm{C}-\mathrm{DAA} 1106(26) . \mathrm{V}_{\mathrm{T}}$ obtained by NLS or GA showed regional distribution similar to $\mathrm{BP}_{\mathrm{ND}}$ in this study, whereas $V_{T}$ was highest in the cerebellum in the ${ }^{11}$ C-DAA1106 study (26).

Although $\mathrm{V}_{\mathrm{T}}$ showed regional distribution similar to $\mathrm{BP}_{\mathrm{ND}}, \mathrm{BP}_{\mathrm{ND}}$ did not correlate with $\mathrm{V}_{\mathrm{T}}$ obtained by NLS or GA. The COVs of $K_{1} / k_{2}$ (mean, 27.5; range, 17.6-34.4) were larger than those of $k_{3} / k_{4}$ (mean, 22.8; range, 19.326.9), indicating that the interindividual variation of $V_{T}$ is mainly caused by the variation of $K_{1} / k_{2}$ rather than $k_{3} / k_{4}$. The same observation was documented in the ${ }^{11} \mathrm{C}$ DAA1106 study, in which we reported that interindividual variation of $K_{1} / k_{2}$ may have been due to errors in plasma input functions, including interindividual variation of plasma protein binding of the radioligand, and that $\mathrm{BP}_{\mathrm{ND}}$ with the NLS method was the most appropriate for the quantification of ${ }^{11} \mathrm{C}$-DAA1106 binding (26). The COVs of

TABLE 2. Average Values of Parameters Estimated by Each Method with 60 -Minute Scan Time $(n=12)$

\begin{tabular}{|c|c|c|c|c|c|c|}
\hline \multirow[b]{3}{*}{ Region } & \multicolumn{6}{|c|}{ Method } \\
\hline & \multicolumn{5}{|c|}{ NLS } & \multirow[b]{2}{*}{$\mathrm{GA}\left(\mathrm{V}_{\mathrm{T}}\right)$} \\
\hline & $K_{1}$ & $K_{1} / k_{2}$ & $k_{3}$ & $k_{3} / k_{4}$ & $\mathrm{~V}_{\mathrm{T}}$ & \\
\hline Cerebellum & $0.183(25.1)$ & $1.38(25.5)$ & 0.097 (28.3) & $3.89(26.5)$ & $5.22(24.5)$ & $6.06(21.5)$ \\
\hline Dorsolateral frontal & 0.172 (31.0) & $1.63(18.7)$ & 0.071 (31.3) & $3.35(22.0)$ & $5.37(22.9)$ & $6.04(23.9)$ \\
\hline Medial frontal & $0.171(28.8)$ & $1.42(18.1)$ & $0.085(28.1)$ & $3.48(21.5)$ & $4.91(25.1)$ & $5.66(23.3)$ \\
\hline Parietal & 0.175 (28.3) & $1.53(17.4)$ & $0.079(27.0)$ & $3.46(20.8)$ & $5.25(23.7)$ & $6.10(22.8)$ \\
\hline Lateral temporal & $0.170(28.1)$ & $1.45(19.8)$ & 0.087 (28.3) & $3.64(23.8)$ & $5.17(23.7)$ & 6.02 (22.3) \\
\hline Medial temporal & $0.147(29.0)$ & $1.27(25.3)$ & $0.089(36.8)$ & $4.31(27.5)$ & $5.32(29.9)$ & $5.50(26.9)$ \\
\hline Occipital & $0.198(24.5)$ & $1.41(22.1)$ & 0.107 (26.9) & $4.06(19.5)$ & $5.67(26.0)$ & $6.68(22.5)$ \\
\hline Anterior cingulate & $0.173(32.0)$ & $1.31(22.9)$ & $0.089(42.7)$ & $3.88(26.6)$ & $4.94(23.7)$ & $5.47(22.7)$ \\
\hline Posterior cingulate & $0.225(24.4)$ & $1.43(35.7)$ & $0.139(35.0)$ & $4.35(26.2)$ & $5.38(27.9)$ & $6.36(25.6)$ \\
\hline Striatum & $0.159(23.2)$ & $1.46(15.2)$ & $0.073(19.4)$ & $3.39(19.1)$ & $4.86(25.5)$ & $5.35(22.2)$ \\
\hline Thalamus & 0.189 (30.5) & $1.56(23.9)$ & $0.094(40.8)$ & $4.49(22.0)$ & $6.45(28.0)$ & $6.66(25.5)$ \\
\hline
\end{tabular}




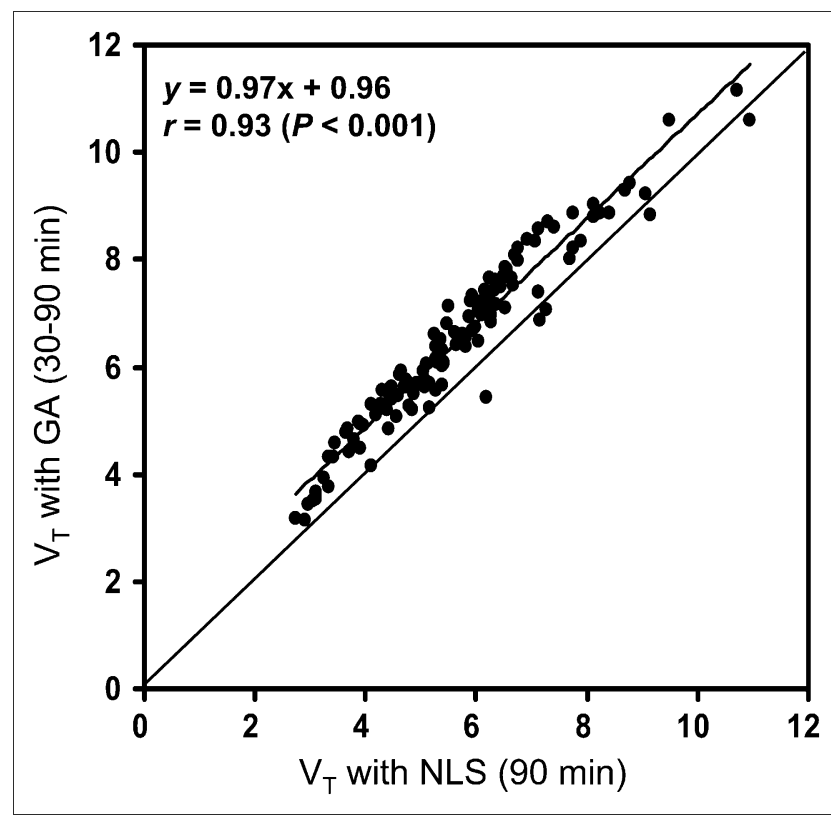

FIGURE 4. Relationship between $V_{T}$ estimated by NLS method and $V_{T}$ estimated by $G A$ method in all regions.

$K_{1} / k_{2}$ of ${ }^{11} \mathrm{C}-\mathrm{AC}-5216$ were similar to those of ${ }^{11} \mathrm{C}$ DAA1106 (mean, 26.2; range, 22.0-30.4). Thus, we concluded that $\mathrm{BP}_{\mathrm{ND}}$ is more appropriate for the quantification of ${ }^{11} \mathrm{C}$-AC-5216 binding than $\mathrm{V}_{\mathrm{T}}$.

For clinical research, a short scan time is preferred. In the present study, the $\mathrm{BP}_{\mathrm{ND}}$ values obtained by the NLS method with a scan time 60 min were in good agreement with those obtained with a scan time of $90 \mathrm{~min}(r=0.87$, $P<0.001)$. $\mathrm{V}_{\mathrm{T}}$ values estimated by NLS or GA with a scan time of $60 \mathrm{~min}$ were also in good agreement with those with a scan time of $90 \min \left(\mathrm{V}_{\mathrm{T}}\right.$ by NLS, $r=0.82, P<0.001 ; \mathrm{V}_{\mathrm{T}}$ by GA, $r=0.92, P<0.001)$. These results suggest that the scan time of 60 min would be valid for clinical studies.

${ }^{11} \mathrm{C}-\mathrm{AC}-5216$ is suitable for the in vivo quantification of $\mathrm{PBR}$ in human subjects, because our recent investigation of animal models has indicated roles of PBR-positive microglia and astrocytes in neurodegenerative processes $(34,35)$. Indeed, the monitoring of PBR levels in living brains could provide mechanistic insights into Alzheimer disease and allied dementias, in consideration of the intimate links between amyloid plaques and reactive astrocytes expressing PBR in mice transgenic for amyloid precursor protein (APP) (35), and between the accumulation of phosphorylated tau proteins and PBR-positive microglia in transgenic mice overexpressing a frontotemporal dementia with parkinsonism-17 (FTDP-17) mutant tau $(35,36)$. Although we have also revealed elevated levels of PBR in multiple regions of Alzheimer disease brains as measured with ${ }^{11} \mathrm{C}$ DAA1106 (28), detection of earlier changes in this component is required for elucidating how the gliotic reactions extensively spread in the course of the aging-disease continuum. In this consideration, our PET assays of PBR in APP and tau transgenics have shown the superiority of ${ }^{11} \mathrm{C}$-AC5216 to other existing radioligands in sensitively capturing glial responses to the hallmark pathologies in these animals (Jun Maeda et al., unpublished data), supporting the potential utility of ${ }^{11} \mathrm{C}$-AC-5216 for the pursuit of neurodegenerative pathologies in humans from an incipient stage.

Accuracy in the measurements of PBR by means of PET would also be critical for gaining statistical power in assessing the neuroinflammatory status after therapies of neurologic conditions. As demonstrated by our PET scans of APP transgenic mice receiving an antibody against amyloid $\beta$ peptide using ${ }^{18}$ F-FEDAA1106 and an amyloid-binding radiotracer, ${ }^{11} \mathrm{C}-\mathrm{Pittsburgh}$ compound-B (37), PBR and amyloid ligands may conjunctively allow clarification of relationships between amyloid removal and glial activations yielded by the amyloid $\beta$ immunization. In addition, the amounts of initially existing amyloid were found to positively correlate with the neuroinflammation provoked by the immunization (37), and this observation highlights the need for rigorous regulation of the glial response within an appropriate range to avoid treatmentinduced microglial overactivations, which may accelerate
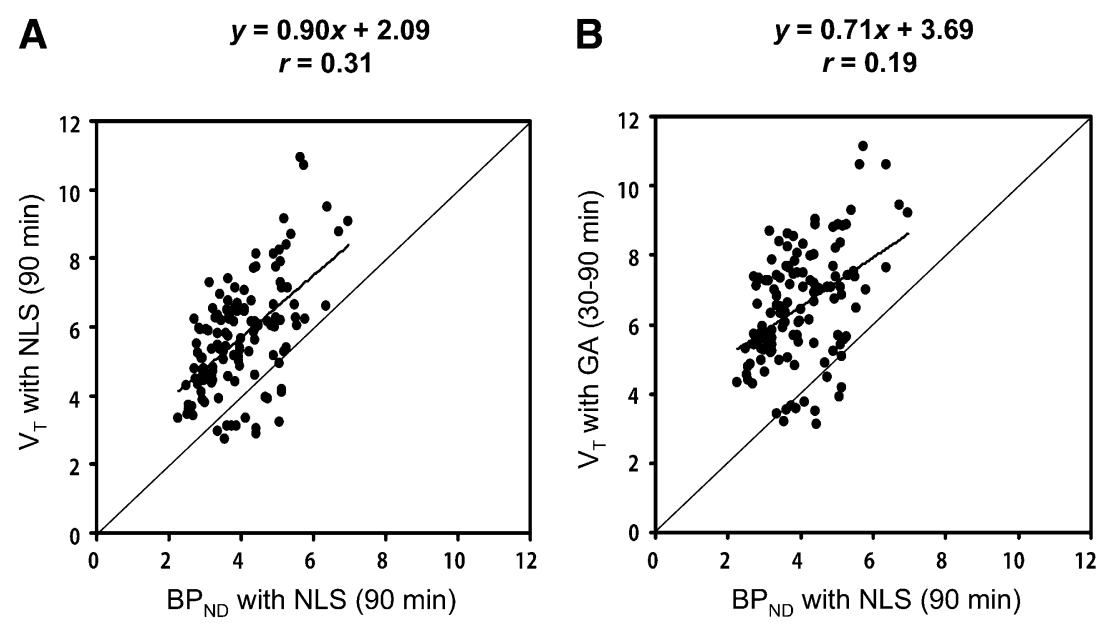

FIGURE 5. Relationship between $B_{\mathrm{ND}}$ estimated by NLS method and $V_{T}$ estimated by NLS (A) or GA (B) method in all regions. 


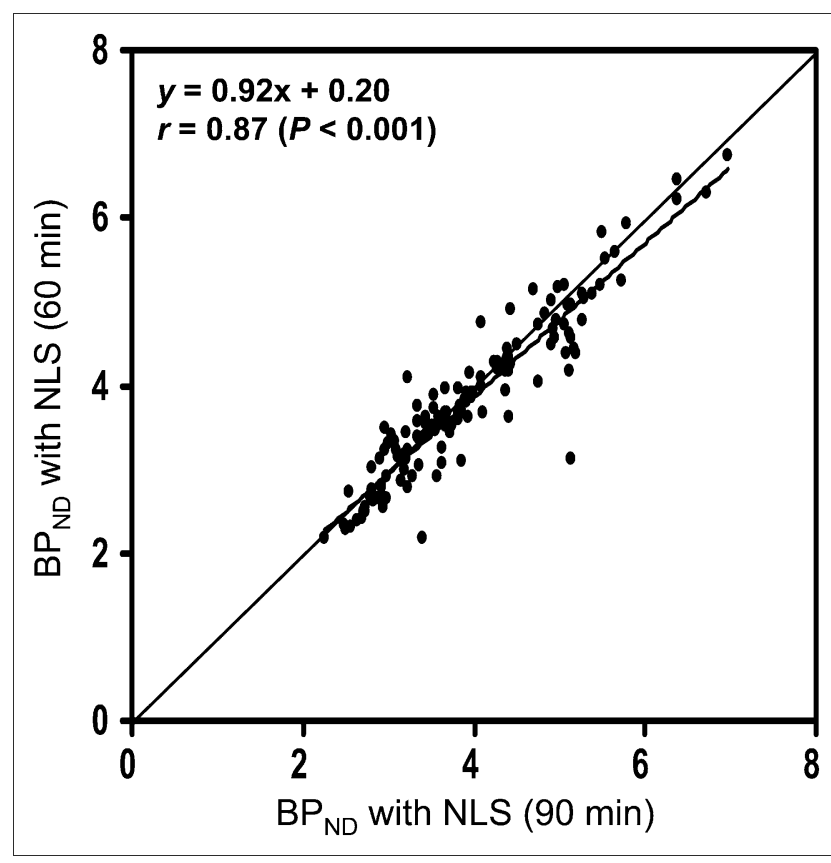

FIGURE 6. Relationship between $\mathrm{BP}_{\mathrm{ND}}$ estimated by NLS method with scan time of $90 \mathrm{~min}$ and that with scan time of $60 \mathrm{~min}$ in all regions.

tau-associated neuropathologies as proven by our previous study on FTDP-17 mutant tau transgenic mice (36). For this purpose, the analytic methods for ${ }^{11} \mathrm{C}$-AC-5216-PET data established here would provide an acceptably precise index of therapeutic and adverse effects.

Longitudinal in vivo PBR imaging with ${ }^{11} \mathrm{C}-\mathrm{AC}-5216$ could be used as a powerful tool for quantitatively estimating the neuroinflammatory pathology and outcomes of disease-modifying treatments in neurodegenerative disorders exemplified by Alzheimer disease.

\section{CONCLUSION}

The regional distribution of ${ }^{11} \mathrm{C}-\mathrm{AC}-5216$ was in good agreement with previous PET studies using PBR ligand in the human brain, for example, ${ }^{11} \mathrm{C}-\mathrm{PK} 11195$ and ${ }^{11} \mathrm{C}$ DAA1106. $\mathrm{BP}_{\mathrm{ND}}$ estimated from NLS did not correlate with $\mathrm{V}_{\mathrm{T}}$ estimated from NLS or GA. In this study, the variation of $K_{1} / k_{2}$ between individuals was larger than that of $k_{3} / k_{4}$. Thus, $\mathrm{BP}_{\mathrm{ND}}$ is more appropriate than is $\mathrm{V}_{\mathrm{T}}$ for the quantitative analysis of ${ }^{11} \mathrm{C}-\mathrm{AC}-5216 .{ }^{11} \mathrm{C}-\mathrm{AC}-5216$ is a promising PET ligand for quantifying PBR in the human brain.

\section{ACKNOWLEDGMENTS}

We thank Katsuyuki Tanimoto and Takahiro Shiraishi for their assistance in performing the PET experiments at the National Institute of Radiological Sciences. We also thank Yoshiko Fukushima of the National Institute of Radiological Sciences for her help as clinical research coordinator. This study was supported by a grant-in-aid for Molecular Imaging
Program from the Ministry of Education, Culture, Sports, Science and Technology (MEXT), Japanese government.

\section{REFERENCES}

1. Anholt RR, De Souza EB, Oster-Granite ML, Snyder SH. Peripheral-type benzodiazepine receptors: autoradiographic localization in whole-body sections of neonatal rats. J Pharmacol Exp Ther. 1985;233:517-526.

2. Anholt RR, Pedersen PL, De Souza EB, Snyder SH. The peripheral-type benzodiazepine receptor: localization to the mitochondrial outer membrane. J Biol Chem. 1986;261:576-583.

3. Antkiewicz-Michaluk L, Guidotti A, Krueger KE. Molecular characterization and mitochondrial density of a recognition site for peripheral-type benzodiazepine ligands. Mol Pharmacol. 1988;34:272-278.

4. Gavish M, Bachman I, Shoukrun R, et al. Enigma of the peripheral benzodiazepine receptor. Pharmacol Rev. 1999;51:629-650.

5. Stephenson DT, Schober DA, Smalstig EB, Mincy RE, Gehlert DR, Clemens JA. Peripheral benzodiazepine receptors are colocalized with activated microglia following transient global forebrain ischemia in the rat. J Neurosci. 1995; 15: 5263-5274.

6. Papadopoulos V, Lecanu L, Brown RC, Han Z, Yao ZX. Peripheral-type benzodiazepine receptor in neurosteroid biosynthesis, neuropathology and neurological disorders. Neuroscience. 2006;138:749-756.

7. Diorio D, Welner SA, Butterworth RF, Meaney MJ, Suranyi-Cadotte BE. Peripheral benzodiazepine binding sites in Alzheimer's disease frontal and temporal cortex. Neurobiol Aging. 1991;12:255-258.

8. Versijpt JJ, Dumont F, Van Laere KJ, et al. Assessment of neuroinflammation and microglial activation in Alzheimer's disease with radiolabelled PK11195 and single photon emission computed tomography: a pilot study. Eur Neurol. 2003;50:39-47.

9. Kassiou M, Meikle SR, Banati RB. Ligands for peripheral benzodiazepine binding sites in glial cells. Brain Res Brain Res Rev. 2005;48:207-210.

10. Zhang MR, Kumata K, Maeda J, et al. $N$-(5-fluoro-2-phenoxyphenyl)- $N$-(2$\left[{ }^{131}\right.$ I] iodo-5-methoxybenzyl)acetamide: a potent iodinated radioligand for the peripheral-type benzodiazepine receptor in brain. J Med Chem. 2007;50:848855 .

11. Boutin H, Chauveau F, Thominiaux C, et al. ${ }^{11} \mathrm{C}-\mathrm{DPA}-713$ : a novel peripheral benzodiazepine receptor PET ligand for in vivo imaging of neuroinflammation. J Nucl Med. 2007;48:573-581.

12. Pappata S, Cornu P, Samson Y, et al. PET study of carbon-11-PK 11195 binding to peripheral type benzodiazepine sites in glioblastoma: a case report. $\mathrm{J} \mathrm{Nucl}$ Med. 1991;32:1608-1610.

13. Pappata S, Levasseur M, Gunn RN, et al. Thalamic microglial activation in ischemic stroke detected in vivo by PET and $\left[{ }^{11} \mathrm{C}\right] \mathrm{PK} 1195$. Neurology. 2000;55:1052-1054.

14. Banati RB, Newcombe J, Gunn RN, et al. The peripheral benzodiazepine binding site in the brain in multiple sclerosis: quantitative in vivo imaging of microglia as a measure of disease activity. Brain. 2000;123:2321-2337.

15. Debruyne JC, Van Laere KJ, Versijpt J, et al. Semiquantification of the peripheral-type benzodiazepine ligand $\left[{ }^{11} \mathrm{C}\right] \mathrm{PK} 11195$ in normal human brain and application in multiple sclerosis patients. Acta Neurol Belg. 2002;102:127-135.

16. Debruyne JC, Versijpt J, Van Laere KJ, et al. PET visualization of microglia in multiple sclerosis patients using $\left[{ }^{11}\right.$ C $]$ PK11195. Eur J Neurol. 2003;10:257-264.

17. Groom GN, Junck L, Foster NL, Frey KA, Kuhl DE. PET of peripheral benzodiazepine binding sites in the microgliosis of Alzheimer's disease. $\mathrm{J} \mathrm{Nucl}$ Med. 1995;36:2207-2210.

18. Cagnin A, Brooks DJ, Kennedy AM, et al. In-vivo measurement of activated microglia in dementia. Lancet. 2001;358:461-467.

19. Goerres GW, Revesz T, Duncan J, Banati RB. Imaging cerebral vasculitis in refractory epilepsy using $\left[{ }^{11} \mathrm{C}\right](R)$-PK11195 positron emission tomography. AJR. 2001;176:1016-1018.

20. Petit-Taboue MC, Baron JC, Barre L, et al. Brain kinetics and specific binding of $\left[{ }^{11} \mathrm{C}\right] \mathrm{PK} 11195$ to omega 3 sites in baboons: positron emission tomography study. Eur J Pharmacol. 1991;200:347-351.

21. Kropholler MA, Boellaard R, Schuitemaker A, et al. Development of a tracer kinetic plasma input model for $(R)-\left[{ }^{11} \mathrm{C}\right] \mathrm{PK} 11195$ brain studies. J Cereb Blood Flow Metab. 2005;25:842-851.

22. Zhang MR, Kida T, Noguchi J, et al. $\left[{ }^{11} \mathrm{C}\right] \mathrm{DAA} 1106$ : radiosynthesis and in vivo binding to peripheral benzodiazepine receptors in mouse brain. Nucl Med Biol. 2003;30:513-519.

23. Maeda J, Suhara T, Zhang MR, et al. Novel peripheral benzodiazepine receptor ligand $\left[{ }^{11} \mathrm{C}\right] \mathrm{DAA} 1106$ for PET: an imaging tool for glial cells in the brain. Synapse. 2004;52:283-291. 
24. Zhang MR, Maeda J, Ogawa M, et al. Development of a new radioligand, $N$-(5fluoro-2-phenoxyphenyl)- $N$-(2-[ $\left.{ }^{18} \mathrm{~F}\right]$ fluoroethyl-5-methoxybenzyl)acetamide, for PET imaging of peripheral benzodiazepine receptor in primate brain. $J$ Med Chem. 2004; 47:2228-2235.

25. Chaki S, Funakoshi T, Yoshikawa R, et al. Binding characteristics of $\left[{ }^{3} \mathrm{H}\right]$ DAA1106, a novel and selective ligand for peripheral benzodiazepine receptors. Eur J Pharmacol. 1999;371:197-204.

26. Ikoma $\mathrm{Y}$, Yasuno $\mathrm{F}$, Ito $\mathrm{H}$, et al. Quantitative analysis for estimating binding potential of the peripheral benzodiazepine receptor with $\left[{ }^{11} \mathrm{C}\right] \mathrm{DAA} 1106 . J \mathrm{Cereb}$ Blood Flow Metab. 2007;27:173-184.

27. Fujimura Y, Ikoma Y, Yasuno F, et al. Quantitative analyses of ${ }^{18}$ F-FEDAA1106 binding to peripheral benzodiazepine receptors in living human brain. $\mathrm{J} \mathrm{Nucl}$ Med. 2006;47:43-50.

28. Yasuno F, Ota M, Kosaka J, et al. Increased binding of peripheral benzodiazepine receptor in Alzheimer's disease measured by positron emission tomography with $\left[{ }^{11}\right.$ C]DAA1106. Biol Psychiatry. 2008;64:835-841.

29. Kita A, Kohayakawa H, Kinoshita T, et al. Antianxiety and antidepressant-like effects of AC-5216, a novel mitochondrial benzodiazepine receptor ligand. $\mathrm{Br} \mathrm{J}$ Pharmacol. 2004;142:1059-1072.

30. Okuyama S, Chaki S, Yoshikawa R, et al. Neuropharmacological profile of peripheral benzodiazepine receptor agonists, DAA1097 and DAA1106. Life Sci. 1999;64:1455-1464.
31. Zhang MR, Kumata K, Maeda J, et al. ${ }^{11} \mathrm{C}-\mathrm{AC}-5216$ : a novel PET ligand for peripheral benzodiazepine receptors in the primate brain. J Nucl Med. 2007;48:1853-1861.

32. Innis RB, Cunningham VJ, Delforge $J$, et al. Consensus nomenclature for in vivo imaging of reversibly binding radioligands. J Cereb Blood Flow Metab. 2007;27:1533-1539.

33. Logan J, Fowler JS, Volkow ND, et al. Graphical analysis of reversible radioligand binding from time-activity measurements applied to $\left[\mathrm{N}^{11} \mathrm{C}-\mathrm{methyl}\right]-$ (-)-cocaine PET studies in human subjects. J Cereb Blood Flow Metab. 1990;10:740-747.

34. Maeda J, Higuchi M, Inaji M, et al. Phase-dependent roles of reactive microglia and astrocytes in nervous system injury as delineated by imaging of peripheral benzodiazepine receptor. Brain Res. 2007;1157:100-111.

35. Ji B, Maeda J, Sawada M, et al. Imaging of peripheral benzodiazepine receptor expression as biomarkers of detrimental versus beneficial glial responses in mouse models of Alzheimer's and other CNS pathologies. J Neurosci. 2008;28:12255-12267

36. Yoshiyama Y, Higuchi M, Zhang B, et al. Synapse loss and microglial activation precede tangles in a P301S tauopathy mouse model. Neuron. 2007;53:337-351.

37. Maeda J, Ji B, Irie T, et al. Longitudinal, quantitative assessment of amyloid, neuroinflammation, and anti-amyloid treatment in a living mouse model of Alzheimer's disease enabled by positron emission tomography. J Neurosci. 2007;27:10957-10968 